\title{
Constipation and Biofeedback; Important Gastrointestinal Symptom but Ignored Initial Management
}

\author{
Ozdal Ersoy ${ }^{1,2 *}$, Yasemin Ecem Temel ${ }^{1,3}$, Hulya Over Hamzaoglu ${ }^{1}$ and Nurdan Tozun ${ }^{2}$ \\ ${ }^{1}$ Acibadem Fulya Hospital, Center for Anorectal Diseases Istanbul, Turkey \\ ${ }^{2}$ Acibadem University, School of Medicine-Internal Medicine, Turkey \\ ${ }^{3}$ Acibadem Fulya Hospital, Pelvic physiotherapist Istanbul, Turkey
}

Submission: February 21, 2017; Published: March 21, 2017

"Corresponding author: Ozdal Ersoy, Acibadem University, School of Medicine, Department of Gastroenterology, Acibadem Fulya Hospital, Besiktas, Istanbul, Turkey, Tel: +905324121656; Email: ozdal.ersoy@acibadem.edu.tr

\begin{abstract}
Constipation is the most common digestive complaint in the general population and its etiology is diverse. Defecatory disorder is a common type of constipation where the patient has difficulty during evacuation due to ineffective relaxation of the anal sphincter and/or inadequate abdominal push. Biofeedback therapy for constipation is a technique used to train a patient's mind to control the way their anorectum works. Biofeedback therapy is unfortunately not available in many centers and also not widely recommended by the physicians although its response rate in the treatment of constipation is about $70-80 \%$. Here, the constipation and biofeedback therapy are shortly reviewed under the light of recent literature and, our study observing the percentage of patients who performed BFT in real world upon recommendation and its clinical response rate in our center for anorectal disease as well as the barriers to biofeedback is discussed.
\end{abstract}

Keywords: Constipation, Biofeedback, Dyssynergy, Defecatory, Anorectal manometry, Balloon expulsion test

Abbreviations: BFT: Biofeedback Therapy; UK: United Kingdom; ARM: Anorectal Manometry; BAT: Baloon Expulsion Test

\section{Introduction}

In order to defecate properly, one needs to be full first and also has to know that he/she is full, then he/she also has to go to squeeze well (able to hold the stool) until sitting on a toilet. When

reached to the toilet, the last but the other two important steps are to open (relax) the back-passage to open the bowel and then close it back when he/she feels completely empty. If any of these steps is deranged by somehow, functional constipation can occur.

Table 1: Causes for chronic functional constipation.

\begin{tabular}{|c|c|}
\hline Primary Causes & Secondary Causes \\
\hline Slow transit constipation (colonic inertia) & Neurological, Metabolic or psychological causes \\
\hline Normal transit constipation & $\begin{array}{c}\text {-Hypothyroidism, Diabetes mellitus, Hyper/hypocalcemia, uremia, } \\
\text { porphyri }\end{array}$ \\
\hline $\begin{array}{l}\text {-misperception of bowel frequency, increased psychosocial distress, } \\
\text { abnormalities of anorectal sensory and motor function }\end{array}$ & -IBS, depression, somatisation, anxiety, perception disorders \\
\hline Outlet delay constipation (Evacuation disorders) & Structural problems \\
\hline $\begin{array}{l}\text { a form of idiopathic constipation in which colon transit measuring markers } \\
\text { move normally through the colon but stagnate in the rectum }\end{array}$ & $\begin{array}{c}\text {-Anal fissure, anal stenosis,rectal prolapsus, rectocele, megarectum } \\
\text { (chagas disease, hirschsprung disease), rectal/colonik malignancies, } \\
\text { diverticulosis, pelvik floor disorders }\end{array}$ \\
\hline
\end{tabular}




\section{Advanced Research in Gastroenterology \& Hepatology}

\begin{tabular}{|c|c|}
\hline $\begin{array}{c}\text { * } \begin{array}{c}* \text { Hirschsprung disease } \\
*\end{array} \\
* \text { Fecal impaction } \\
* \text { Megarectum, megacolon } \\
* \text { Pelvic Floor disorders } \\
* * \text { Dyssynergic defecation } \\
\text { (failure to relax of puborectalis or external anal sphincter muscle during } \\
\quad \text { defecation) } \\
* * \text { Rectocele, intesusception } \\
* * \text { Pelvic organ prolapsus }\end{array}$ & $\begin{array}{l}\text { Concomitantly taken medications } \\
\text {-Muscle relaxants,some anti-depression drugs , opiate anlgesics, iron or } \\
\text { calcium supllements, some anti-hypertensives. } \\
\text { Life and diet styles } \\
\text {-Inadequate fluid intake, inadequate fiber and food intake, immobility, } \\
\text { advanced age, inefficient access to toilet, muscle tiredness. }\end{array}$ \\
\hline
\end{tabular}

Constipation is the most common gastrointestinal disorder in adults and may be regarded as disordered movement of stool through the colon or anorectum since, with few exceptions, transit through the proximal gastrointestinal tract is often normal. Slowing of colonic transit may be idiopathic or may be due to secondary causes. Constipation is simply defined as bowel symptoms (difficult or infrequent passage of stool, having hard stool and excessive straining, feeling of incomplete evacuation, need for digital maneuvers) that may occur either in isolation (primary) or secondary to another underlying disorder. Etiology of constipation is summarised in Table 1 and extensive list of other causal factors is well described elsewhere in the literature [1]. It is also very important to remember that, constipation can be drived from a singluar entity or multiple overlapping etiologies which may lead to the need for basic or advanced treatment modalities.

Very careful and meticulous history taking (duration of the symptom, consistency of the stool, defecation frequency and the need of digital maneuvers and excessive straining, sensation of incomplete evacuation, concomitant drug use and diseases, alarm symptoms) and physical examination (especially rectal digital examination including squeeze and pushing maneuvers) are valuble elements for the initial assessment of the patient with chronic constipation. Laboratory evaluation, endoscopic evaluation, radiology studies and anorectal physiology testing (ARM, anorectum sensations, BAT) should be performed only in selected individuals. Anorectal manometry with or without BAT, is a valuable diagnostic test especially in patients with evacuation pathologies [2].

As an initial management of constipation, conservatory treatment (patient education, toileting habits and behavior modification, trial of dietary changes, trial of fiber, basic laxative therapy and bowel retraining and/or biofeedback) without diagnostic testing can be considered when alarm features are absent. Severe, intractable, slow transit constipation is rare and may be treated with surgery, but with extreme caution; patients should be referred to specialized centers for a full evaluation prior to surgery if needed [3].

Dyssynergic defecation which is a grossly unrecognized evacuation problem and a particular type of chronic constipation, means a dyscoordination between the rectum and the anal sphincter and puborectalis muscles during defecation. In patients with dyssynergic defecation, defecation is ineffective due to failure of the anal sphincter to relax, or inappropriate contraction of the puborectalis and external anal sphincter muscles or inadequate abdominal propulsive force to increase theintrarectal pressure (pushing failure) [4]. These patients usually have life-long constipation and experience significant difficulty with passing stools but are unaware that they have this type of constipation. However, they often don't seek help beyond using over-the-counter laxatives, and some doctors also aren't aware of the condition either, therefore and consequently these patients cannot be treated well.

Management of defecatory dysfunction involves suppositories, biofeedback therapy (BFT), or botulinum toxin injections into the puborectalis/anal sphincter muscles. Patients with both slow transit and defecatory dysfunction should be reevaluated after treatment of the defecatory dysfunctionbecause of the risk of overlapping.

Biofeedback is an operant conditioning and learning through reinforcement, and BFT is a behavioral approach in constipation treatment that can be used to correct the involuntary paradoxical contraction (rather than relaxation) of the constipated patient's pelvic floor muscles and external anal sphincter while having bowel movement (evacuation) [5,6]. It is also a valuable treatment method for many constipated patients having associated disorders like urinary or sexual dysfunctions.

However, BFT is not widely available and used; it has not been well standardized among the trainers therefore the results may vary at different centers. However, where available, it is simple, attractive, alternative and satisfactory for patients especially with pelvic floor dysfunction (dyssynergic defecation) and severe constipation as it retrains the pelvic muscles and provides the potential for treatment without laxatives and protects the patients from over performed or complicated colorectal surgeries (e.g. hemorrhoidectomy, sphincterotomy, colonic resections).

In the literature, many methods of BFT can be observed. Various instruments, including anal plugs rectal balloons, and anorectal manometer catheters, have been used to monitor external anal sphincter pressures during attempted expulsion of the apparatus. The patient watches/ hears the recordings of sphincter pressure traces or EMG activity and is asked to modify inappropriate responses through trial and error, this type of BFT is known as visual/auditory BFT. During visual biofeedback training, a probe with sensors is inserted rectally which the sensor detects the muscle signals from the anus and rectum and displays them visually 
on a TV monitor. While sitting on the commode the subjects are able to see how these muscles are contracting or relaxing and with the visual feedback learn how to coordinate them correctly to improve their push and relaxation movements. Generally the patient attends to this type of sessions once a week for 4-6 weeks therapy. Unfortunately it is only offered at few specialized centers because insurance generally do not cover this rarely recognized treatment modality [7]. Whereas UK type bowel retraining/biofeedback programmable assessment of the patient's bowel symptoms, general health, diet, any medications and other psychosocial factors that may influence the patient's bowel function. Using this information and the results of any investigations that the patient may have had, the nurse discusses the likely causes of the problems and plans a treatment programme for the patient to work on together. The therapy involves teaching the patient how to retrain the muscles used to empty and control the bowels and the nurse shows the patient (lying on left lateral position) how to use his/her muscles while the patient is simulating defecation with a balloon inside his/her anorectum during a minimum one hour lasting session. Most patients have one or two further appointments or phone call- interviews (with the same physician/nurse) at approximately one or two month intervals [8]. All biofeedback techniques aim people to be more aware of unconscious or involuntary bodily functions involved in defecation and help individuals relearn the normal process of having a bowel movement.

As mentioned before, BFT is not universally available in many centers where constipated patients are seen. Like in Turkey, clinical trials about the efficacy of biofeedback in anorectal disorders and pelvic floor dysfuntions are very rare because of lack of centers and/or medical stuff (physician, pelvic floor physiotherapist and/ or continence nurse) performing or recommending BFT to the concerned patient.

In our study, we retrospectively observed 437 patients who were referred to our 'Center for anorectal diseases' between 20132016 .We did the study to find out primarily: what percentage of the patients with constipation who are recommended BFT had performed BFT in real-life and what are the main obstacles for not attending to BFT. Secondary aim was to find the success rate and its factors of BFT.

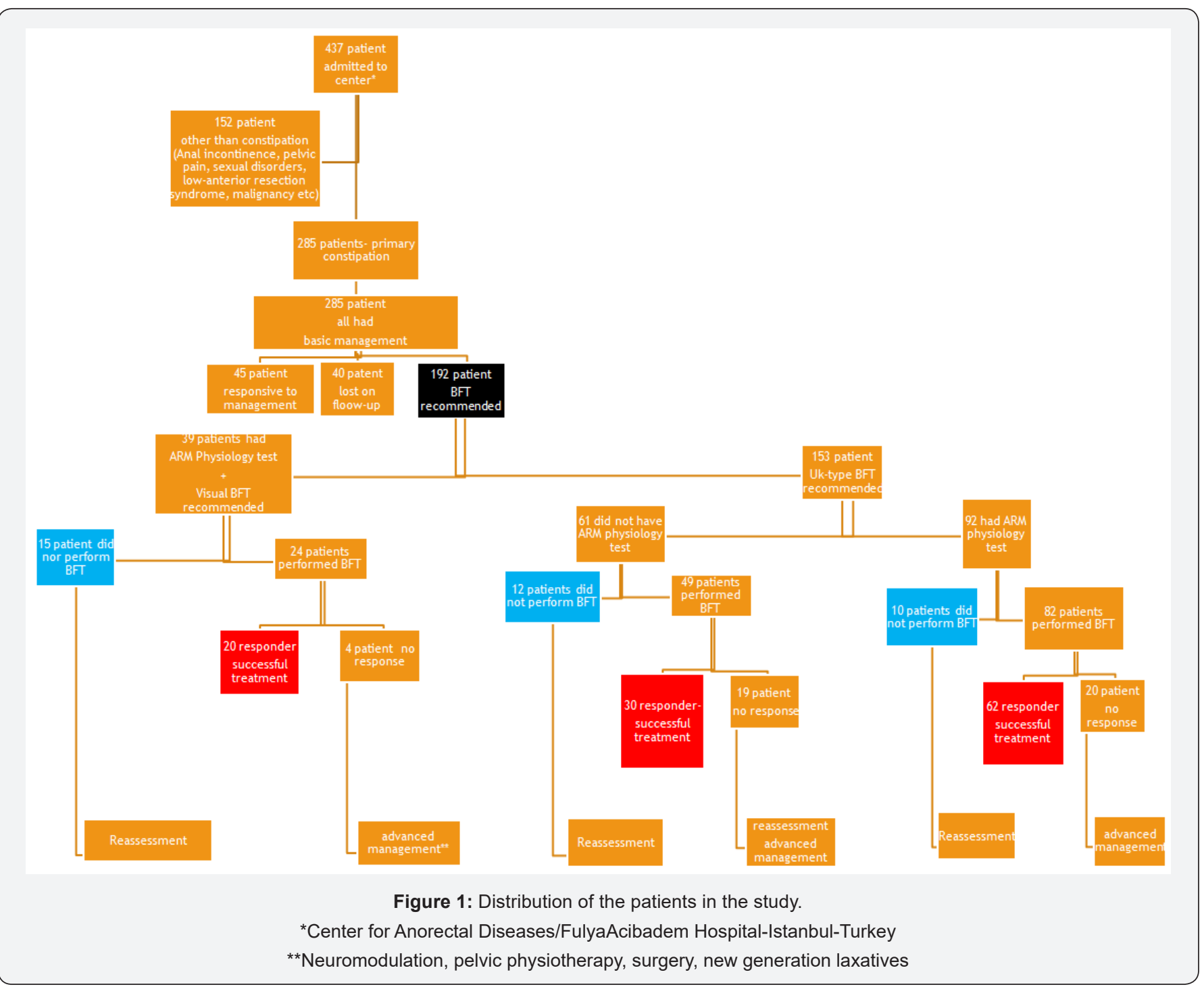


The study showed that, among 437 patients, 285 had chronic functional constipation and/or its complications (haemorrhoids, anal fissure). After the initial assessment of the constipated patients, all are recommended basic/standard managements (patient education, correct toilet positioning, planning convenient toileting habits, and behavior modification, trial of dietary changes, trial of fiber, basic laxative therapy) and then the patients are called back to control visits after 4-6 weeks. Fourteen percent of the patients are lost during follow-up and $16 \%$ of them had corrected bowel function at the end of 4-6 weeks of standard therapy. The rest, 192 patients who were unresponsive basic managements, had performed bowel retraining (UK-type BFT or visual BFT). Both types of BFT are performed under the guidance of both physician and physiotherapist/nurse. Visual BFT is performed in patients only after anorectal physiology tests (anorectal manometry, anal/ rectal electrical sensation test, balloon expulsion test and/or defecography) had been performed; whereas for $40 \%$ patients whom UK-type BFT was performed had no anorectal physiology tests done previously. $60 \%$ of the patients who were referred to visual BFT, did attend to their BFT sessions and bowel movement improvement was possible in nearly $85 \%$ of patients through biofeedback whereas $90 \%$ of patients who were recommended UK-type BFT after physiology tests performed, did attend to their BFT and $75 \%$ of these patients showed improvement in their symptoms. Among patients whom UK-type BFT is performed without performing any anorectal physiology tests, $80 \%$ of them performed BFT with the success rate of $60 \%$. The patients who did not perform BFT, are followed up and reassessed for the reasons and the patients who did not get any improvement with BFT, advanced treatment modalities and/or further diagnostic tests are discussed and/or planned. Summary of the patients (in numbers) are summarised in Figure 1.

The main reasons for not performing visual BFT when recommended are; being expensive (due to different coverage problems by health insurance companies), being not common in Turkey thus showing doubt to treatment, long duration of treatment (once a week for at least 6-8 weeks) and transportation problems due to living in long distance from the center. Whereas the main reason for not to apply UK-type BFT is the doubt to treatment modality probably due to the heterogenity of the description of BFT. The cost and the treatment durations seem to be negative factors for visual BFT in our study. When BFT (both kinds) is recommended after physiology tests are done, number of patients who accepts to perform BFT is more than the ones who did not perform the anorectal tests before. The BFT is more effective in patients with defecatory symptoms rather than slow transit constipation and also more success is observed in highly motivated and interactive patients during the sessions.

\section{Discussion}

Chronic constipation is a well known and a frequently seen symptom in many medical clinics but unfortunately less attention is given to the appropriate non pharmacological treatment modalities like BFT. It is a chronic debilitating problem for the patient with significant negative impacts in quality of life and social functioning however many patients still do not have much knowledge about BFT modality due to the less availability.

Functional constipation (without any organic cause) is a learned behavior, so it can be unlearned as well via BFT. It aims to bring about symptom relief by teaching good evacuation dynamics, to improve sphincter coordination and tone, and replace bad toileting behavior with normal habits and to decrease stress/worry by explaining symptoms and encouraging realistic expectations. During BFT trained therapists-including physicians, nurses, and physical or occupational therapists-teach patients strengthening exercises or relaxation techniques that can be performed to reduce their symptoms. The sessions vary in number, length and frequency, and techniques can take place in a doctor's office and be continued at the patient's home. Biofeedback, in constipated patients is associated with improved gut transit and autonomic innervation [9]

Randomized controlled trials from specialized centers report response rates of $60 \%-80 \%$ for defecatory disorders. Whether this therapy is as successful outside of trials or specialized centers remains unclear.BFT is an effective outpatient treatment for constipation in long term as well as it is non-invasive, free from sideeffects and well tolerated. However, real life experiences about BFT shows that less than half of patients recommended BFT undergo the therapy [10]. As also observed in our study, the main causes of this, is the difficulty in its availability, the paucity of the specialized centers and the trainers and insurance-coverage policies. If these obstacles are overcome, the success rates in many hetero genous populations undergoing BFT are only slightly less than published randomized trials as it is also seen in our study.

\section{Conclusion}

Constipation is one of the most common digestive problem and Nearly $25-30 \%$ of affected people have dyssynergic defecation, in which muscles used for bowel movements do not work well, however BFT is labor-intensive and very effective when welldone for defecatory disorders but unfortunately BFT use is not as common as it is needed. Thus, both the physicians and the patients need to be trained and motivated about the use of BFT more widely and prospective trials or real-life experiences are war rented to handle the barriers to BFT.

\section{References}

1. Andrew C, Storr M (2011) The pathophysiology of chronic constipation. Can J Gastroenterol 25(Suppl B): 16B-21B.

2. Rao SS, Bharucha A, Chiarioni G, Felt-Bersma R, Knowles C, Allison Malcolm, et al. (2016) Anorectal disorders. Gastroenterology 150: $1430-1442$.

3. Emmanuel A (2011) Current management strategies and therapeutic targets in chronic constipation. TherAdvGastroentero 4(1): 37-48.

4. Rao SS, Welcher KD, Leistikow JS (1998) Obstructive defecation: a failure of rectoanal coordination. Am J Gastroenterol 93(7): 1042-1050.

5. Rao SS, Seaton K, Miller M, Brown K, Nygaard I, et al. (2007) Randomized controlled trial of biofeedback, sham feedback, and standard therapy for dyssynergic defecation. Clin Gastroenterol Hepatol (5): 331-338. 
6. Heymen S, Scarlett Y, Jones K, Ringel Y, Drossman D, Whitehead WE (2007) Randomized, controlled trial shows biofeedback to be superior to alternative treatments for patients with pelvic floor dyssynergiatype constipation. Dis Colon Rectum 50(4): 428-441.

7. Heymen S, Jones KR, Scarlett Y, Whitehead WE (2003) Biofeedback treatment of constipation: a critical review. Dis Colon Rectum 46(9): 1208-1217.

8. Lembo A (2010) Chapter19/constipation. In: Feldman M, Friedman L, Brandt L (Eds.), Sleisenger \& Fordtran's Gastrointestinal And Liver
Disease: Pathophysiology, Diagnosis, Management ( $9^{\text {th }}$ edn) Brandon/ Hill Medical,Univ of Texas, Dallas, USA, PP. 270-296

9. Emmanuel AV, Kamm MA (2001) Response to a behavioural treatment, biofeedback, in constipated patient is associated with improved gut transit and autonomic innervation. Gut 49(2): 14-219.

10. Jodorkovsky D, Dunba KB, Gearhart Sl, Sten EM, Clarke JO (2013) Biofeedback therapy for defecatorydysfunction:"real life" experience. J Clin Gastroenterol 47(3): 252-255.

\section{Your next submission with Juniper Publishers will reach you the below assets}

- Quality Editorial service

- Swift Peer Review

- Reprints availability

- E-prints Service

- Manuscript Podcast for convenient understanding

- Global attainment for your research

- Manuscript accessibility in different formats

( Pdf, E-pub, Full Text, Audio)

- Unceasing customer service

Track the below URL for one-step submission https://juniperpublishers.com/online-submission.php 